\section{ST segment elevation myocardial infarction with normal coronary arteries}

\section{CASE PRESENTATION}

A middle-aged patient presented to the emergency department with intermittent chest pain of 4-hour duration. The patient had been recently diagnosed with metastatic adenocarcinoma of the colon and was receiving 5-fluorouracil (5-FU)-based chemotherapy at the time of presentation. The ECG at presentation showed $1 \mathrm{~mm}$ ST segment elevation in leads II, III and aVF, with reciprocal changes in leads aVL, V1 and V2 (figure 1A). Serum cardiac troponin I level was elevated at $0.11 \mathrm{ng} / \mathrm{mL}$ (normal: $0.00-0.02 \mathrm{ng} / \mathrm{mL}$ ). The patient was given sublingual nitrate and loading doses of aspirin, clopidogrel and atorvastatin, and was taken up for coronary angiography with an intent to perform primary percutaneous coronary intervention.

The images of the coronary angiogram are shown in figure 2. The patient was angina-free by this time. A repeat ECG done 30 min after coronary angiography is shown in figure 1B. Two-dimensional transthoracic echocardiogram revealed normal left ventricle (LV) systolic function and no regional wall motion abnormality.
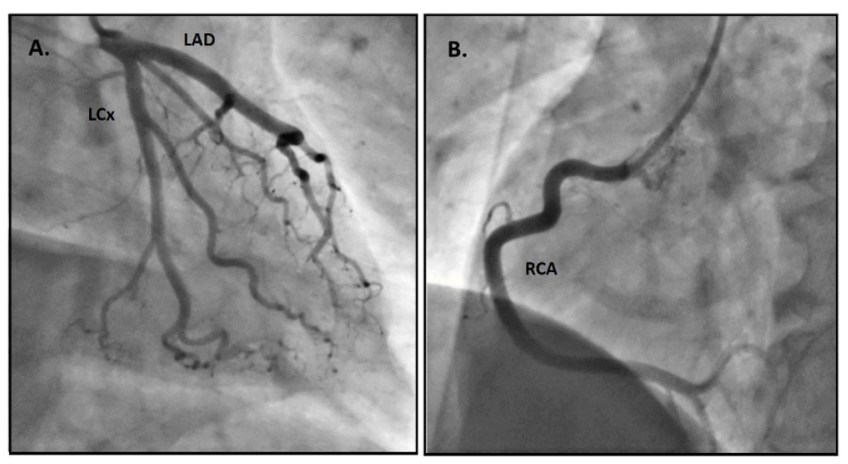

Figure 2 Images of the coronary angiogram of the patient. (A) Right anterior oblique view with a caudal angulation showing left anterior descending (LAD) artery and left circumflex (LCX) artery. (B) Left anterior oblique view with a cranial angulation showing right coronary artery (RCA).

\section{QUESTION}

What is the likely mechanism of myocardial infarction in this patient?

1. In situ coronary artery thrombosis with spontaneous recanalisation.

2. Epicardial coronary artery vasospasm.

3. Coronary artery embolism.

4. Coronary microvascular dysfunction.

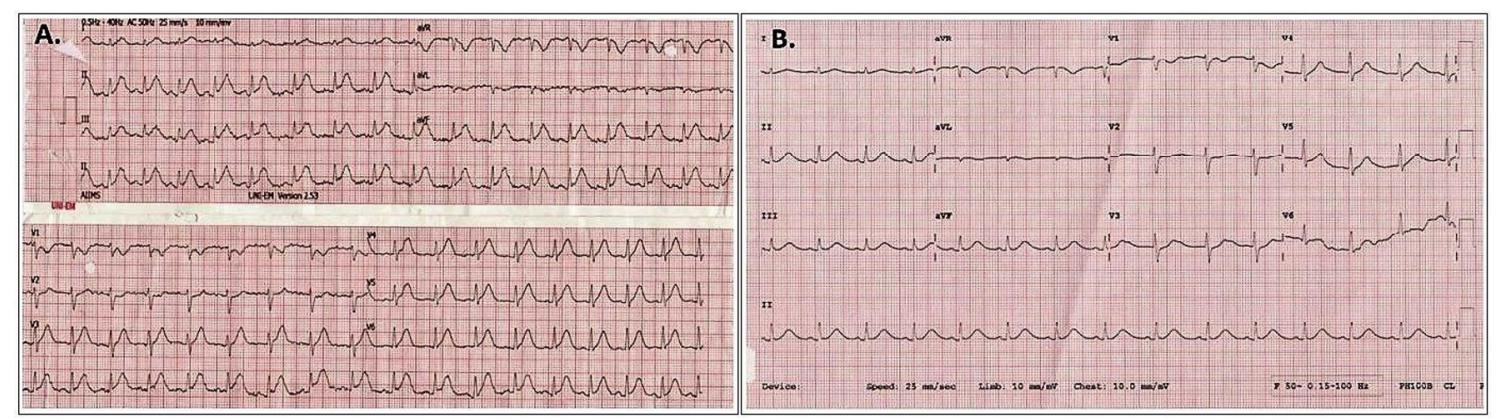

Figure 1 (A) 12-lead ECG done at presentation to the emergency department. (B) 12-lead ECG done 30 min after coronary angiography. 


\section{ANSWER: B}

Myocardial infarction with non-obstructive coronary arteries may be caused by coronary vasospasm, thrombosis/emboli, dissection, microvascular dysfunction, myocarditis and Takotsubo cardiomyopathy. In this case, the clue to the diagnosis was the temporal relationship of 5-FU administration with the onset of angina.

Cardiotoxicity is a well-documented adverse effect of 5-FU with an incidence of $1.2 \%-18 \%$. It usually occurs during the first cycle and manifests clinically within 72 hours of exposure. Angina is the predominant symptom and is usually associated with ECG changes, commonly ST segment deviation. Less common forms of presentation include acute coronary syndrome, ventricular arrhythmias, cardiomyopathy, cardiogenic shock and sudden death. Imaging usually reveals non-obstructive coronary arteries and normal LV function. ${ }^{1}$

Coronary vasospasm is considered as the main mechanism in 5-FU-related cardiotoxicity. 5-FU has been shown in vitro to cause direct, endothelium-independent contraction of the vascular smooth muscle through activation of protein kinase-C. ${ }^{2}$ In vivo studies have confirmed the vasospastic properties of this drug. ${ }^{3}$

In our case, coronary vasospasm is the likely mechanism as suggested by the following:

- Temporal association of symptoms in relation to 5-FU infusion.

- Presentation with angina with ST segment elevation (figure 1A).

- Resolution of symptoms and ECG changes (figure 1B).

- Normal coronary arteries (figure 2).

- Normal LV function.

\section{Siddharthan Deepti, Raghav Bansal, Sandeep Singh}

Department of Cardiology, All India Institute of Medical Sciences, New Delhi, India

Correspondence to Dr Sandeep Singh, Department of Cardiology, Cardiothoracic Sciences Center, All India Institute of Medical Sciences, New Delhi 110029, India; drssandeep@hotmail.com

Contributors SD was involved in the interpretation of data and revising the article critically for important intellectual content. RB was involved in the acquisition and interpretation of data, and in drafting the article. SS was involved in the interpretation of data, planning and revising the article critically for important intellectual content.

Funding The authors have not declared a specific grant for this research from any funding agency in the public, commercial or not-for-profit sectors.

Competing interests None declared.

Patient consent Not required.

Provenance and peer review Not commissioned; externally peer reviewed.

(c) Author(s) (or their employer(s)) 2018. No commercial re-use. See rights and permissions. Published by BMJ.

\section{(A) Check for updates}

To cite Deepti S, Bansal R, Singh S. Heart Asia 2018;10:e011084.

Heart Asia 2018;10:e011084. doi:10.1136/heartasia-2018-011084

\section{REFERENCES}

1 Polk A, Vaage-Nilsen M, Vistisen K, et al. Cardiotoxicity in cancer patients treated with 5-fluorouracil or capecitabine: a systematic review of incidence, manifestations and predisposing factors. Cancer Treat Rev 2013;39:974-84.

2 Mosseri M, Fingert HJ, Varticovski L, et al. In vitro evidence that myocardial ischemia resulting from 5-fluorouracil chemotherapy is due to protein kinase C-mediated vasoconstriction of vascular smooth muscle. Cancer Res 1993;53:3028-33.

3 Südhoff T, Enderle MD, Pahlke M, et al. 5-Fluorouracil induces arterial vasocontractions. Ann Oncol 2004;15:661-4. 